\title{
Damning with faint praise
}

\section{Karen Chapman}

Taking on a new role with considerable responsibility, a senior colleague (already on the management team) welcomed me with the comment: "I'm sure you will do a good job-you are very conscientious". Does he think I am not up to the job? How do I convey my acknowledgement of the "compliment" and agreement with the importance of so-called soft qualities like conscientiousness and integrity, while at the same time emphasising the other things I think I can contribute like leadership, vision, and innovative solutions?

There are layers of complexity in this single comment, contributing to what Savigny terms cultural sexism: "significant, invisible, [and] normalising” (2014, p. 796) cultural practices, norms and values that frame women's experience within the academy. Two strands in particular stand out: benevolent sexism, and the contrast between words used about women and those used about men.

Benevolent sexism can be insidious, portraying women as warm and supportiveas long as they conform to the roles assigned to them by men, and do not challenge men's authority (Dumont, et al., 2010). An integral part of benevolent sexism is its suggestion that women are less competent than men, and this can become, for a woman, a self-fulfilling prophecy. As Dumont et al. argue: Be too kind to a woman, she'll feel incompetent. Benevolent sexism is the obverse of hostile sexism and the two are closely related - see Glick \& Fiske (1996; 2001) for discussion of ambivalent sexism theory - but benevolent sexism is often more difficult to spot, and less easy to counter, often because its language is complimentary.

"Very conscientious" is a 'grindstone' compliment. In their paper examining gender differences in recommendation letters, Dutt et al. demonstrate how:

Implicit biases can surface via the way applicants are described in recommendation letters, with women being described as less confident and forceful, and more nurturing and helpful than men, and receiving fewer 'standout' adjectives such as superb and brilliant, and more 'grindstone' adjectives such as hardworking and diligent" (Dutt et al., 2016, p. 1).

They reference previous studies in fields including chemistry, psychology and medicine where similar biases have been identified, noting that these 'grindstone' adjectives are as likely to be used by women of other women, as by men.

\section{Ingredients}

- A slightly patronising male colleague, who is trying to be welcoming and friendly. 


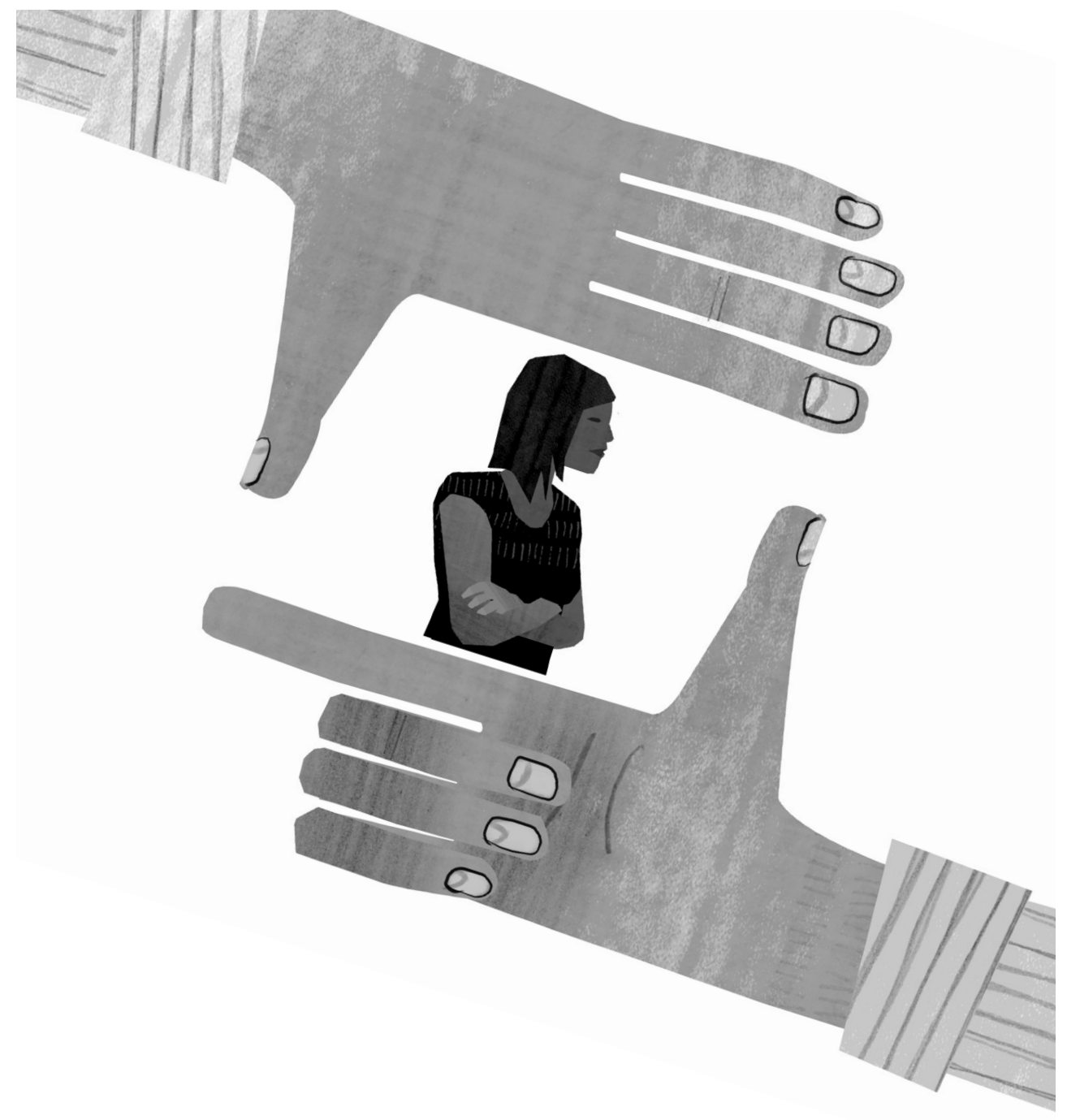

- A committee, management team or other senior group of people, in which men predominate.

\section{Method}

1. Take one moment to digest.

2. Accept compliment as it is: "Thank you".

3. Agree with the importance of being conscientious: "I hope that everyone on the committee/team is conscientious". Invite clarification: "I hope you invited me to the committee to contribute more than just conscientiousness..." and wait expectantly for his reply. Give it a decent length of time. If he has any self-awareness, he will realise what he said and squirm a bit.

4. If he is suitably embarrassed and flounders a little, then offer help and an example of how you have already performed well in a leadership role: "I will also bring a different perspective, being female, as well as (for example) - 
lateral thinking. When I was on the suchand-such committee, it was my idea to... (here, give an example) and I steered through... (give another example)."

5. Use the opportunity to demonstrate your anticipation of the role: "What do you see as the biggest challenges currently facing us?" and "What solutions do you envisage?", for example. Explore his willingness to credit others: "Are those your personal views or those of the committee as a whole?"

6. Finish up by emphasising your commitment and involvement: "Good. I think I will be able to contribute to that. I'm looking forward to joining the team" and move on.

\section{Warning}

If the recipient is completely lacking in self-awareness, a rather more blunt approach may be needed!

\section{Cook's perspective}

Interestingly, I haven't had a similar experience since. I think too, that gender equality is advancing rapidly (in the UK) as the person who made that comment last year moved from selecting all male nominees for awards a year ago, to having around $30 \%$ female this year. Amazing how much more aware people are of unconscious bias and the like! 